\title{
Inovação no Processo de Arrecadação do IPTU com a Implantação do PIX
}

\author{
Nome: João Vitor Lemos da Silva ${ }^{1}$ \\ Universidade Federal Fluminense \\ e-mail:jviclemos07@gmail.com
}

\section{RESUMO}

O novo método de pagamento denominado PIX, lançado em 2020, tem um grande potencial para ser inserido no setor público. Um exemplo disso é o pagamento do Imposto sobre a Propriedade Predial e Territorial Urbana - IPTU, por meio desta ferramenta já incorporada em algumas cidades brasileiras. Com isso, a pesquisa buscará responder o questionamento: "Como o PIX poderá ser uma alternativa de inovação na arrecadação do IPTU?” Dessa maneira, o estudo possui como objetivo geral apresentar o pagamento de IPTU via PIX como uma alternativa de contribuição. Conivente a isso, os objetivos específicos buscam apontar os impostos coletados no Brasil, o IPTU nos municípios, descrever o método de pagamento PIX e, por fim, apresentar, dentro do setor público brasileiro, alguns entes que adotaram o PIX como possibilidade de pagamento do IPTU na sua estrutura, evidenciando, com precisão, a alternativa de contribuição para o setor. A metodologia de pesquisa escolhida para desenvolver este trabalho foi através da pesquisa exploratória, por meio do método de revisão bibliográfica. Por fim, é de conhecimento que os processos atuais de pagamentos demoram dias e alguns demandam tempo, deixando de ser prático. Por meio de procedimentos inovadores como o pagamento de impostos via PIX, através da internet, é proporcionada agilidade e praticidade nos procedimentos de compensação do imposto coletado.

Palavras-chave: Setor Público; Inovação; PIX; Tecnologia; Impostos.

\section{ABSTRACT}

The new payment method called PIX, launched in 2020, has a great potential to be inserted in the public sector, an example of this is the payment of the Property Tax - IPTU through this tool, already incorporated in some Brazilian cities. Therefore, this research seeks to answer how the PIX can be an innovation alternative in the collection of the IPTU? So, the general objective of this research is to present the payment of IPTU via PIX as a payment alternative. Thus, the specific objectives seek to point out the taxes collected in Brazil, the IPTU in the municipalities, describe the PIX payment method and, finally, present within the Brazilian public sector, some entities that adopted the PIX as payment for IPTU in their structure. It was chosen to develop this work through exploratory research by means of the bibliographic review method. Finally, it is nothing new that the current payment processes take days and some demand time, making it no longer practical and through innovative procedures such as the payment of taxes via PIX, over the internet, it provides agility and practicality in the procedures for clearing the collected tax.

Keywords: Public Sector; Innovation; PIX; Technology; Taxes.

[Submetido em 07-out-2021 - Aceito em: 18-jan-2022 - Publicado em: 25-fev-2022\} 


\section{Introdução}

Inovação é a criação de novas realidades. Essa afirmação realça características essenciais da inovação. Em primeiro lugar, ao ser "criação" ela é, ao mesmo tempo, o processo e o resultado de fazer existir algo que não havia e, por extensão, de oferecer novo feitio ou utilidade a algo que já existia. Ao ser também entendida como processo, a inovação deixa de ser percebida como fruto exclusivo de lampejos de inventividade e engenhosidade, que certamente são bem-vindos e importantes. Desse modo, ela passa a ser compreendida como um conjunto estruturado de ações ou operações visando a um resultado e, portanto, a inovação é propensa a ser estimulada, promovida e gerida. É, por conseguinte, um campo pluridisciplinar fértil para aplicação de conhecimentos e práticas de administração, direito, economia, engenharia, medicina e psicologia, entre outros. (PLONSKI, 2017)

A inovação deve ser buscada continuamente, e hoje está diretamente ligada à tecnologia. Assim, novas ideias são necessárias para desenvolver novos modelos de negócios e melhorar a experiência do cliente. Dessa forma, o setor público também carece de inovação, possibilitando agilidade em seus procedimentos, processos e melhorias no atendimento ao público que é a população (BRANDÃO e BRUNO-FARIA, 2013).

Em paralelo à conceituação de inovação, a Prefeitura do Eusébio (2021) foi o primeiro município do Brasil a utilizar o PIX para recebimento de tributos. Os boletos do Imposto sobre a Propriedade Predial e Territorial Urbana, ou IPTU, já trazem o QR Code que direciona para o pagamento com PIX. Com isso, a pesquisa buscará responder o questionamento: "Como o PIX poderá ser uma alternativa de inovação na arrecadação do IPTU?" Com isso, o estudo possui como objetivo geral apresentar o pagamento de IPTU via PIX como uma alternativa do recolhimento do IPTU. Complacente ao propósito integral, os objetivos específicos buscam apontar os impostos coletados no Brasil, o IPTU nos municípios, descrever o método de pagamento PIX e, por fim, apresentar, dentro do setor público brasileiro, alguns entes que adotaram o PIX como possibilidade de pagamento do IPTU na sua estrutura, evidenciando, a alternativa de contribuição do meio de pagamento pelo PIX para o setor.

Em relação à justificação da pesquisa, ela é uma forma de contribuir com o meio acadêmico em que está inserida, além de ser possível enriquecer a temática abordada. Evidencia-se como uma forma de agregar conhecimento em seu meio social, onde se pretende apresentar um material concreto, possibilitando a compreensão dos leitores, mesmo que sem conhecimento técnico, que buscam maior compreensão sobre o tema.

Para o estudo exploratório, foi utilizado o método de revisão bibliográfica a partir da realização de pesquisas bibliográficas na literatura como artigos, livros, periódicos, dissertações, teses, artigos de sites de notícias, de artigos em sites de prefeituras e similares. Foi realizado, juntamente, o modelo de leitura que recebe o nome de leitura seletiva, onde é feita uma identificação profunda para levantamento de informações consistentes para a pesquisa. O registro das informações foi feito utilizando o formato, nome e ano da publicação. Ademais, foi realizada uma leitura analítica, possibilitando a ordenação das informações coletadas. E, por fim, para justificar o problema de pesquisa, serão apresentados casos de três cidades para explicar a inovação do sistema PIX nos pagamentos do IPTU. 


\section{Fundamentação Teórica}

\subsection{Setor Público Brasileiro}

O setor público brasileiro enquadra-se como aqueles onde são ofertados serviços à população, sendo estes de responsabilidade do Estado; sejam eles em educação, setor social, saúde, assistencial, jurídico, entre outros. O setor público, diferente do setor privado, age em benefício da sociedade e sem fins lucrativos (SANTOS e SANO, 2016).

O setor público brasileiro é composto por três esferas: federal, estadual e municipal; e por três poderes: Executivo, Legislativo e Judiciário. Compete ao poder executivo a administração do Estado, cumprindo as normas e leis do país e, mas, sobretudo, recomendar os planos de ação e comandar os interesses públicos. Esse poder é praticado no nível federal pelo Presidente da República e seus ministros, secretários, comitês de políticas públicas e órgãos da administração pública (SANTOS e ROVER, 2019).

Ademais, titular do poder executivo, no seu papel de chefe de Estado, é responsável por definir as relações internacionais e governamentais, assim definir ações econômicas e de políticas públicas. Além disso, o presidente deve estabelecer interlocução política com o legislativo, tendo o poder de aprovar ou vetar leis aprovadas pelo congresso. No nível estadual, o poder executivo está concentrado no governador e em seus secretários de estado; enquanto no nível municipal, o poder administrativo está concentrado no prefeito e em seu secretariado municipal (QUEIROZ e CKAGNAZAROFF, 2010).

Ao Legislativo, cabe legislar - ou seja, elaborar, assentir as leis e supervisionar o Executivo -, sendo as duas funções fundamentalmente importantes e significativas. Adota encargo de controle político-administrativo e financeiro-orçamentário. Para o primeiro controle, depende da análise da gestão do Estado e até mesmo da capacidade de questionar o comportamento do poder administrativo; para o segundo controle, concordar ou desaprovar as contas públicas. Esse poder é realizado pelos deputados federais e senadores em grau federal; deputados estaduais em grau estadual e vereadores em grau municipal (SANTOS e SANO, 2016).

Tratando-se do Judiciário, compete interpretar as leis e julgar os processos mediante as normas constitucionais e as leis formuladas pelo legislador; e aplicar a lei aos casos específicos que lhe sejam submetidos por conflitos de interesses. O Judiciário é representado pelos juízes, ministros e desembargadores. Atentando-se com cautela, pela Constituição Federal, os promotores de justiça não são integrantes do Poder Judiciário, mas sim do Ministério Público. Portanto, a separação de poderes é uma maneira de descentralizar o poder e livrar-se dos abusos de autoridade, de forma que um poder controle o outro (SANTOS e ROVER, 2019).

\subsection{Inovação}

A literatura dedicada ao tema inovação leva em consideração que existem estudos sobre uma gama de tipos de inovação, tais como: produto, processo, serviço, gestão, comunicação, entre outros (CAVALCANTE et al., 2017).

Sobre o conceito de inovação, há uma definição estabelecida por Ramella. Uma primeira definição literal do conceito descreve uma mudança em um estado de coisas 
existentes, a partir da introdução de algum elemento novo. Logo, o ato de inovar implica numa relação diacrônica entre um estado de coisas anterior e um estado modificado por esse elemento novo (WOLFFENBUTTE, 2018).

Assim, Ramella propõe cinco pontos de esclarecimento para o debate sobre inovação (WOLFFENBUTTE, 2018). São eles:

1. Inovação é processual. Trata-se de uma atividade complexa que compreende uma série de fenômenos interconectados, porém não é necessariamente linear, com fluxo e direção estáveis no tempo (WOLFFENBUTTE, 2018);

2. Inovação é relacional. É relativa a um período e um contexto, ou seja, só pode ser compreendida em confronto com um estado de referências anteriores; e depende da contribuição de outros sujeitos, seja na fase de criação ou na fase de implementação (WOLFFENBUTTE, 2018);

3. Inovação é diferente de mudança. Essa última é mais ampla e não necessariamente envolve algo de novo, ao contrário da inovação que implica sempre uma novidade - fazer feitos novos ou coisas que já estão sendo produzidas de uma forma nova. (WOLFFENBUTTE, 2018);

4. Inovação é diferente de invenção. Invenção significa conceber um novo produto ou processo; inovar implica em colocar em prática pela primeira vez esta nova ideia. Enquanto a primeira permanece confinada no âmbito da elaboração, a inovação envolve as consequências de sua implementação. (WOLFFENBUTTE, 2018);

5. Inovação não é necessariamente positiva. Diferentemente da noção de progresso, a introdução de uma novidade nem sempre leva aos êxitos esperados. Devido às consequências impremeditadas, a inovação pode falhar ou não ser benéfica para o inovador ou para a comunidade de referência (WOLFFENBUTTE, 2018).

\subsubsection{Inovação No Setor Público}

Inovação é geralmente um termo relacionado ao setor privado. Por sua vez, o setor público muitas vezes é sinônimo de lentidão, burocracia e incompetência. Mas não necessariamente precisa ser assim. Se o lucro e a participação de mercado são positivos para o setor privado, para o setor público o resultado da inovação pode se refletir em serviços públicos mais eficazes ou mais econômicos mensuráveis, ou em melhorias de processos que gerem efeitos mais subjetivos - como justiça, confiança, pertencimento a uma comunidade (BRANDÃO e BRUNO-FARIA, 2013).

Além disso, a inovação no setor público é uma causa fundamental para o melhoramento dos serviços oferecidos à população. Hoje, o cidadão visa ser ajudado com agilidade e competência. Desperdiçar tempo para determinar um serviço é algo cada vez menos admitido pelos cidadãos, que reivindica educação e um suporte de elevado grau (SCHWELLA, 2005).

A inovação colabora para as organizações públicas determinarem dificuldades por intermédio de novas disposições institucionais e de tentativas, projetos e práticas inovadoras bem cumpridas no setor público (BRANDÃO e BRUNO-FARIA, 2013). 
A capacidade de responder da forma esperada, no que concerne às organizações públicas em inovarem seus serviços, consente que a sociedade, os cidadãos e os usuários de serviços públicos demonstrem a segurança e a legalidade do Estado. Assim sendo, qualificar a agilidade das organizações públicas e dominar quais circunstâncias colaboram para o triunfo de experiências inovadoras é uma agenda para as investigações sobre esse tema em quesito no Brasil (CAVALCANTE et al., 2017).

Para ter a compreensão do porquê o Estado vem ponderando a transcendente parte das ameaças no capitalismo moderno, é imprescindível detectar o caráter coletivo da inovação. As instruções sobre os sistemas de inovação retratam que, à maneira que se prossegue em sistema de inovação aberta, há uma propensão na elevação das relações de correlação, destravando os bloqueios de cooperação entre os setores público e privado (SCHWELLA, 2005).

A legalidade do desempenho do Estado é que há não só uma tarefa que o diferencia de outras organizações, mas também o poder e as ferramentas para elaborar elementos que de outra maneira não apareceriam. É necessário asseverar, todavia, que o crescimento econômico distendido pela inovação seja não somente engenhoso, mas também abrangente e defensável (BRANDÃO e BRUNO-FARIA, 2013).

Os agentes políticos estão cada vez mais inflexíveis, incitando e abraçando não só a inovação no setor privado, mas também construindo políticas públicas e serviços públicos inovadores. Porém, alguns impedimentos ainda se mantêm na existência do serviço público brasileiro, que devem ser retirados para dar espaço a condutas mais inovadoras (CAVALCANTE et al., 2017).

Diante de questões complexas e mudanças rápidas na sociedade contemporânea, a inovação é fundamental. No setor público, a inovação é uma área do conhecimento que fornece uma base sólida para os planos, políticas, projetos e práticas implementados por governos e organizações públicas, e visa obter uma ampla gama de resultados e impactos positivos na qualidade de vida dos cidadãos (BRANDÃO e BRUNO-FARIA, 2013).

Em todas as políticas públicas, seja no campo social, de infraestrutura ou econômico, a fase de avaliação tem se tornado cada vez mais um fator interno na tomada de decisões. Assim sendo, os envolvidos em práticas inovadoras devem dedicar parte de seu tempo à avaliação e monitoramento dos resultados e impactos obtidos, de forma a manter o suporte e os recursos necessários à plena implantação do projeto (SCHWELLA, 2005).

\subsubsection{Inovações Econômicas na Administração Pública}

A inovação econômica pode ser entendida como um processo institucionalizado de mudança, que introduz elementos de novidade econômica: nas necessidades que venham satisfazer, nos bens e serviços que venham a produzir; ou nos modos de produção, distribuição e de uso. Diferente da concepção formal de economia, que assume o mercado abstrato como única forma de distribuição, esta definição é baseada nos sistemas econômicos concretos, processos históricos de interação entre as pessoas e seus ambientes na produção, distribuição e consumo de meios materiais para a satisfação de necessidades (POLANYI, 1980, apud WOLFFENBUTTE, 2018). 
Dessa forma, a concepção de inovação econômica permite deslocar o foco, quase exclusivo, da inovação tecnológica, centrada na produção e na busca de soluções tecnológicas, para inserir a noção de inovação como um processo retroativo de introdução de novos produtos, novos conhecimentos ou novos processos produtivos, no interior de um contexto (WOLFFENBUTTE, 2018).

Logo, trata-se de um processo relacionado a um meio, em que a aplicação dessa novidade traz consequências econômicas para esse meio. Portanto, espera-se que o meio também exerça alguma influência nessa relação, criando não apenas novos espaços para a inovação, mas também novos vetores para a novidade. Essa leitura da inovação econômica permite concebê-la como um processo social complexo, que pode ser influenciado tanto por arranjos de políticas públicas que visam incentivar a colaboração e o desenvolvimento de determinadas inovações quanto por impedimentos jurídicos, políticos e culturais capazes de obstruí-la (TRIGILIA, 2007 apud WOLFFENBUTTE, 2018).

\subsection{Impostos No Brasil}

Por definição, impostos são tributos que não têm destino particular. Em outras palavras, o Estado pode usar recursos nas áreas que considerar melhores, mesmo que uma série de leis restrinja o uso desses recursos estabelecendo despesas mínimas obrigatórias para todos os entes federados em certas áreas. Por não ter destinação definida, por exemplo, o dinheiro arrecadado com o Imposto de Renda (IR) pode ser usado para pagar salários de funcionários públicos e também para investimentos (MEDEIROS e SOUZA, 2013).

Os brasileiros pagam 73 tributos nas esferas federais, estaduais e municipais entre impostos, taxas e contribuições. Os tributos são "pagamentos" de forma obrigatória que os brasileiros e as empresas (pessoas físicas e jurídicas) deverão pagar ao estado para custear as atividades do governo. Os impostos podem ser impostos, doações e despesas (LIMA e REZENDE, 2019).

Além disso, os impostos têm outra particularidade - podem possivelmente ser divididos entre entidades governamentais, se exigido por lei. Assim, por exemplo, a União pode dividir impostos com estados e municípios. O IR e o Imposto sobre Produtos Industriais (IPI) são casos em que a união partilha impostos com outras entidades (CAPUANO, 2015).

A Constituição Federal prevê a geração de tributos, cabendo aos entes federais a cobrança desses tributos e a destinação dos recursos obtidos com os tributos. Ainda, há diversas leis federais complementares para estabelecer o recolhimento de impostos, doações e taxas. Os municípios e estados têm as próprias regras tributárias (BALEEIRO, 2010).

Os impostos federais são administrados sob ordenamento jurídico pelos arts. 153 e 154 da Constituição Federal, sendo os impostos de IOF, Impostos Sobre Grandes Fortunas, Impostos Residuais Da União, Importação, IEG (Imposto Extraordinário de Guerra), Impostos de Exportação, ITR (Imposto Sobre Propriedade Territorial Rural), IPI, Imposto de Renda, PIS e COFINS, entre outros alguns deles. (LIMA e REZENDE, 2019). 
Já no que diz respeito aos impostos estaduais, existem 3 tipos, que são eles: Imposto sobre Circulação de Mercadorias e Serviços (ICMS), Imposto sobre a propriedade de veículos automotores (IPVA) e Imposto de transmissão causa mortis e doação (ITCMD). (LIMA e REZENDE, 2019).

\subsubsection{Impostos Municipais}

Com o novo modelo de organização político-administrativa, elaborado pela Constituição Federal de 1988 - C.F/88, os municípios passaram a atuar de forma autônoma, como descreve o art. $1^{\circ}$ da lei suprema: "A República Federativa do Brasil, formada pela união indissolúvel dos Estados e Municípios e do Distrito Federal, constitui-se em Estado Democrático de Direito". Dessa forma, o pacto federativo brasileiro implantou a distribuição de competências entre os membros, visando a descentralização de recursos e atribuições. (DUARTE e CHAGAS,2017).

De acordo com a C.F/88 no seu art. 156, os municípios detêm a competência tributária para instituir os seguintes impostos:

I - Propriedade predial e territorial urbana - IPTU;

II - Transmissão "intervivos" a qualquer título, por ato oneroso, de bens imóveis, por natureza ou acessão física, e de direitos reais sobre imóveis, exceto os de garantia, bem como cessão de direitos a sua aquisição- (ITBI) e

III - Serviços de qualquer natureza (ISS), não compreendidos no art. 155, II, definidos em lei complementar. (DUARTE e CHAGAS,2017).

\subsubsection{Imposto Sobre A Propriedade Predial E Territorial Urbana - IPTU}

De acordo com o art. 156, I, Constituição Federal, IPTU, é a propriedade de imóvel localizado na área urbana do município, que pertence à jurisdição do município e do distrito federal. A jurisdição tributária é uma norma jurídica estruturada, promulgada em nível constitucional, que estipula que os políticos (autoridades federais, estaduais, distritais e municipais) podem legislar em matéria tributária (CAPUANO, 2015).

As normas estruturais, que limitam a capacidade dos objetos normativos, delineiam possíveis áreas materiais para a elaboração de novas normas jurídicas, representadas por um conjunto de fatos, situações ou relações que são objeto de disciplinas jurídicas, e as normas podem constituir autorizações, obrigações ou proibições dessas normas (BALEEIRO, 2010).

O assunto da pronúncia é especificado pelas normas de exposição. Ele deve executar as ações ou série de ações necessárias para a regulamentação da produção eficaz no sistema jurídico. É essa norma que restringe o sujeito competente e demais sujeitos jurídicos, por meio das relações jurídicas (LIMA e REZENDE, 2019).

Consequentemente, no que se refere ao imposto objeto desse artigo, é de competência dos municípios e do Distrito Federal o definirem por meio de lei ordinária (regra-matriz de incidência tributária), bem como proporcionar todas as demais modificações que se efetivarem fundamentais (CAPUANO, 2015). 
O IPTU (Imposto Predial e Territorial Urbano) é recolhido todos os anos de todos os que possuem instalações nas cidades, sejam elas comerciais, prédios ou residenciais. Como o IPTU arrecada bens, o contribuinte deve pagar o valor do imóvel em seu nome. Se for um, apenas um é tributado; se forem dez, paga-se dez impostos, cada um com seu valor característico (MEDEIROS e SOUZA, 2013).

Se o imóvel é urbano, mas é apenas um terreno sem construção, então é pago o IPTU (Imposto Territorial Urbano). Entretanto, se o imóvel estiver localizado fora da divisa da cidade, o ITR (Imposto Territorial Rural) é cobrado mediante contagem e alíquotas distintas do IPTU (LIMA e REZENDE, 2019).

O IPTU foi elaborado primariamente, com o título de "Décima Urbana", por um Alvará indicado em 27 de junho de 1808, pelo até então príncipe Regente João Maria José Francisco Xavier de Paula Luís Antônio Domingos Rafael de Bragança, que posteriormente viria a ser o Rei Dom João VI, com objetivo de preencher os cofres da corte Portuguesa recém estabelecida no Brasil. Posteriormente, em 1834, a competência se dissociou e passou para as províncias (CAPUANO, 2015).

A constituição de 1988 estipulou os princípios das funções sociais da propriedade. No momento, o IPTU contribui para os custos do projeto e do desenvolvimento municipal, mas sempre obedece às obrigações sociais da propriedade (BALEEIRO, 2010). Portanto, há uma diferença no valor cobrado dos contribuintes titulares de bens que não favorecem para o desenvolvimento das funções sociais, formando um mecanismo que prevê o aumento gradativo dos impostos municipais, obrigando os proprietários a se preocuparem com a função social da propriedade. Portanto, o IPTU é uma ferramenta por meio da qual pode ser garantida a eficácia da função social da propriedade (LIMA e REZENDE, 2019).

O IPTU é recolhido por meio das prefeituras. Sendo assim, cada cidade brasileira tem um valor distinto, que pode mudar conforme avaliação do imóvel. O objetivo desse imposto é arrecadar recursos para a melhoria da cidade. Para calcular o valor do IPTU, utiliza-se o chamado valor de mercado do imóvel, que é o preço definido pela própria prefeitura. Este preço é diferente do valor de mercado (o preço pelo qual o imóvel é comprado ou vendido) (CAPUANO, 2015).

A forma de pagamento do IPTU pode ser à vista, no começo do ano, ou dividido ao decorrer do ano. A opção depende do planejamento financeiro de cada pessoa. Embora não haja taxas adicionais, para incentivar o pagamento em dinheiro, a maioria das prefeituras oferece descontos em pagamentos únicos. Os princípios para liberação do IPTU também podem variar de uma cidade para outra. Em algumas cidades, aposentados e pensionistas pagam menos. Outras cidades fornecem a isenção pelo valor da propriedade (MEDEIROS e SOUZA, 2013).

\subsection{Métodos De Pagamentos Digitais}

Os pagamentos digitais, ou seja, aqueles que podem ser realizados em qualquer lugar desde que o usuário conte com o equipamento necessário, com algum aplicativo instalado e acesso à internet, estão cada vez mais presentes no mundo moderno atual. Sua facilidade de uso atrai até mesmo pessoas menos familiarizadas com o meio digital. Sendo assim, são usados em grande escala em compras on-line e até em pagamentos de contas de luz, por exemplo. (BUFANO et al,2020). 
Com o avanço da modernidade, as facilidades criadas pela tecnologia vêm conquistando cada vez mais espaço no Brasil. Dentre as que estão em ascensão, o pagamento por meios digitais é a que tem mais destaque, de acordo com o Banco Central. (ECONOMIA SC,2020).

As Estatísticas de Pagamentos de Varejo e de Cartões no Brasil, do ano passado, apontam que a utilização de dinheiro físico vem decrescendo no país. Consequentemente, o uso de caixas eletrônicos também. (ECONOMIA SC,2020). Correlacionado a isso, o Banco Central do Brasil refere-se a uma tendência ao uso de transações via internet:

As transações por internet banking e mobile banking seguem em tendência de alta, com aumento de $4 \%$ e de $17 \%$, respectivamente, em relação ao ano anterior, e corresponderam a $76 \%$ do total de transações realizadas em 2019. O número de ATMs em operação, por sua vez, reduziu-se em cerca de 3\%, encerrando 2019 em 171.284terminais, disse o Banco Central do Brasil (ECONOMIA SC,2020).

O cenário brasileiro de meios de pagamentos digitais deve mudar, veementemente, nos próximos anos, em resposta a dois fatos recentes: a pandemia da Covid-19 e o lançamento do PIX. Ambos impulsionam a digitalização e simplificação das transações em ritmo jamais antes visto (LIMA e FRANCISCO,2021).

\subsubsection{Principais meios de pagamentos digitais utilizados no Brasil:}

Boleto: $\mathrm{O}$ pagamento realiza leitura ou é necessário digitar o código de barras. $\mathrm{O}$ dinheiro fica disponível somente no dia útil seguinte após o boleto ser pago. Só pode ser pago em dias úteis. A emissão do boleto tem regras mais complexas, custosas e não há aviso quando a transação é feita. (NUBANK,2021)

Cartão de débito: $\mathrm{O}$ cartão de débito funciona como um meio de pagamento ligado diretamente com sua conta corrente ou conta poupança. Para isso, é importante atentar para o saldo que você possui em sua conta, pois, diferente do cartão de crédito, o pagamento via cartão de débito é feito exatamente no momento da compra. (BMG,2020)

Cartão de crédito: $\mathrm{O}$ cartão de crédito é um meio de pagamento com um limite de crédito pré-definido, que permite ao consumidor comprar bens e/ou serviços nos estabelecimentos que aceitam cartão. O consumidor só paga por esses valores no dia do vencimento da fatura do cartão. (ECONOMIA UOL,2019)

\section{e DOC \\ 2.4.2 Principais meios de transferências digitais utilizados no Brasil: TED}

O TED (Transferência Eletrônica Disponível) e o DOC (Documento de Crédito) são duas modalidades de transferência de dinheiro. Seja na boca do caixa ou pela internet. Quem quer enviar uma quantia de uma conta para outra, precisa escolher uma dessas opções. A diferença é que, no caso da TED, o dinheiro cai no mesmo dia - se realizado antes das $17 \mathrm{~h}$-, e permite transferências maiores que 5 mil reais. Já no DOC, o dinheiro cai no dia seguinte e o valor máximo é de 4999,99 reais. (NUBANK, 2021)

\subsubsection{Principais meios de transferências digitais utilizados no Brasil: PIX}


Tal como os meios digitais de transações bancárias acima aboradados, o PIX realiza ambos os formatos, ou seja, pagamentos e transferências. Apesar de ser uma palavra com apenas três letras, PIX não é uma sigla nem significa um conceito específico. De acordo com o Banco Central, o novo meio de pagamentos foi batizado com o nome PIX, porque o termo lembra tecnologia, transações e PIXels (os pontos luminosos de uma tela). Ou seja: PIX é um nome, uma marca criada para identificar o novo meio de pagamentos de uma forma simples, efetiva e muito fácil de ser lembrada (NUBANK,2021).

O PIX é uma ferramenta de pagamento por forma eletrônica e imediata de transferência bancária elaborada pelo Banco Central do Brasil. As transações bancárias podem ser realizadas a qualquer momento pelo celular, sejam em contas correntes, de poupança ou de pagamento. O PIX foi lançado em 5 de outubro de 2020 e começou a operar em 16 de novembro do mesmo ano. Permite transferências gratuitas e instantâneas de uma conta para outra (BANCO CENTRAL DO BRASIL, 2020). Ao contrário do TED e DOC, há um limite de tempo, que pode demorar mais de um dia para chegar à pessoa que o receberá.

O PIX pode ser usado para pagamentos entre pessoas, entre pessoas e instituições, entre instituições (como provedores de pagamento) e pagamento de taxas e impostos (BANCO CENTRAL DO BRASIL, 2020).

Segundo o Banco Central (2021), os objetivos de PIX são:

Elevar a agilidade de pagamentos e transferências financeiras;

Ampliar a concorrência e competência do mercado;

Diminuir o custo, expandir a segurança e qualificar a experiência do cliente;

Encorajar os subsídios eletrônicos no varejo;

Proporcionar a inclusão financeira.

O PIX é gratuito para pessoas físicas, o que torna mais fácil para os consumidores comuns realizarem transações bancárias, porque os métodos tradicionais dos bancos exigem taxas. Proprietários de lojas, empresários e outros usuários registrados como pessoas jurídicas podem ter que pagar uma pequena taxa fixa para cada transação (SOARES, 2020). Segundo a normatização do Banco Central (2021), a Instituição Financeira é quem estipula o valor a ser cobrado (ou se há dispensa), mas o valor deve ser bem abaixo ao valor recolhido quando o PIX não é usufruído.

Os procedimentos de segurança do PIX exigem prova de identidade quando alguém que não seja o proprietário tenta usar a chave. Os criminosos não podem registrar o $\mathrm{CPF}$ da vítima em sua conta, pois cada conta só pode registrar um CPF (SOARES, 2020).

Os pagamentos PIX podem começar a partir de $\mathrm{R} \$ 0,01$, e as Instituições Financeiras podem definir um valor máximo para evitar fraudes e lavagem de dinheiro. No entanto, o Banco Central não define um limite máximo para as transações PIX (BANCO CENTRAL DO BRASIL, 2021). Os bancos com mais de 500.000 clientes precisam estar associados ao PIX, mas as plataformas e instituições menores também adotaram novos meios e procedimentos de pagamento para tornar fácil as transações bancárias e minimizar os custos. De acordo com o Banco Central (2021), as principais vantagens do PIX incluem: 
finais de semana;

O serviço estará à disposição 24 horas do dia, todos os dias, incluindo até

As transações serão realizadas num prazo de 10 segundos;

diferentes;

Sistema vasto de participação, permitindo pagamentos entre instituições

Força de mecanismos e soluções para asseverar a segurança das transações;

Ferramenta multiproposta, que poderá ser utilizada para pagamentos autônomos de categoria e valor da transação, relativo a duas ou mais pessoas, empresas e governo;

Conhecimento posto à disposição para o usuário;

Transações realizadas em alguns segundos; maneiras disponíveis para quem vai receber em tempo real;

Investigações relevantes para conciliação conseguirão cursar próximo com a ordem de pagamento, viabilizando a automação de técnicas e a conciliação dos pagamentos.

O cadastro no PIX é rápido e, de acordo com a regulamentação do Banco Central (2021), as Instituições Financeiras devem tornar visível o ícone de acesso PIX, para que seja fácil localizar o lugar de acesso. Para utilizar o serviço, é indispensável cadastrar pelo menos uma "chave PIX", que é uma maneira de identificar o cliente. A chave estará rigorosamente próxima aos dados pessoais e bancários, e as transações bancárias podem ser feitas sem a imposição de inserir informações como conta, agência e CPF. A pessoa pode optar pelas seguintes chaves para o PIX (BANCO CENTRAL DO BRASIL, 2021):

Documentos como CPF ou CNPJ;

E-mail;

O número de celular;

Uma chave aleatória (mistura de letras e números gerados aleatoriamente).

Há também um código QR ( $Q R$ Code), que pode ser usado para compras ou pagamento, mas precisa ser registrado com chave PIX para usá-lo. O código QR pode ser estático (elaborado para uma única transação) ou dinâmico (gerado para diversas transações). As desvantagens são quase nulas. Mesmo que ainda seja implementado um sistema novo, ele não deleta os usuários do conjunto bancário, nem mesmo os que não possuem a chave PIX. Então, a lista de desvantagens do PIX inclui (BANCO CENTRAL DO BRASIL, 2021):

Não autoriza realizar transações divididas;

Não há maneira que o valor possa ser estornado, caso uma pessoa tenha enviado de forma errada, por exemplo;

Necessita que o aparelho esteja vinculado à internet para processar a transação instantaneamente.

As facilidades utilizadas para fraude e crime não são umas das falhas do PIX; são situações do domínio do crime, ou seja, não podem ser consideradas umas das irregularidades do PIX, mas sim uma questão de segurança (BANCO CENTRAL DO 
BRASIL, 2020). No entanto, o Banco Central (2021) estipula que as instituições financeiras devem estabelecer regras para acabar com violações, como a lavagem de dinheiro e fraude. Portanto, é por isso que alguns bancos e empresas de fintech definem a quantidade máxima de transações no PIX.

\subsubsection{Pagamento via PIX}

Com a ajuda de tecnologia elaborada e associação entre governos municipais e o Banco do Brasil e/ou Caixa Econômica Federal, as prefeituras passaram a recolher impostos por meio do sistema de pagamento instantâneo implementado pelo Banco Central. Uma nova existência que ajuda o pagamento de milhões de brasileiros, incluindo contribuintes que precisam pagar taxas e impostos municipais (BANCO DO BRASIL, 2021).

A implementação deste novo método de pagamento é consistente com a pregação de que os órgãos da administração pública modernos simplificam a vida dos cidadãos em termos dos serviços públicos que prestam. E, conforme for caminhando, as "cidades podem se tornar perspicazes", na qual a inovação tecnológica está cada vez mais integrada à vida cotidiana. PIX é uma tecnologia emergente que continuará a existir (BANCO DO BRASIL, 2021).

A tendência da digitalização dos meios de pagamentos foi estimulada ainda mais pela pandemia da Covid-19. A crise sanitária impôs a necessidade de isolamento social e deu impulso à adoção de meios de pagamento que reduzissem o compartilhamento de objetos. O contexto ajuda a explicar o fenômeno chamado PIX, sistema de pagamentos instantâneo e gratuito para pessoas físicas e jurídicas, criado pelo Banco Central em 2020, que já é o segundo meio de pagamento mais utilizado no país, praticamente empatado com o dinheiro. O dado faz parte da pesquisa realizada pela Confederação Nacional de Dirigentes Lojistas (CNDL) e pelo Serviço de Proteção ao Crédito (SPC Brasil), em parceria com o Sebrae. De acordo com o levantamento, as modalidades de pagamento mais utilizadas pelos brasileiros são: dinheiro (71\%), PIX (70\%), cartão de débito (66\%) e cartão de crédito (57\%). (CONFEDERAÇÃO NACIONAL DE DIRIGENTES LOJISTAS, 2021).

A preferência pelo PIX é justificada para 83\% dos usuários pela rapidez e a praticidade, seguido de evitar ou minimizar contato físico com máquinas e/ ou pessoas (34\%) e pela segurança (32\%). (CONFEDERAÇÃO NACIONAL DE DIRIGENTES LOJISTAS, 2021).

Em menos de três meses, o PIX superou as operações de TED e do DOC, somadas. A partir de abril passado, suas transações ficaram acima, também, dos boletos. E, no final de outubro, o PIX já respondia por $72 \%$ das operações. Considerando TED, DOC, TEC, boleto e cheque, foram 1,2 bilhão de transações no mês. A quantidade de operações PIX já ultrapassou outros meios como cartão pré-pago, transferência intrabancária e débito direto. (BANCO CENTRAL DO BRASIL,2021).

\section{Metodologia}

\subsection{Classificação da Pesquisa}


O estudo justifica-se de modo qualitativo, pois busca identificar as iniciativas de inovação na implantação do PIX como meio de pagamento do IPTU. Segundo Godoy (1995), na abordagem qualitativa o estudo empírico é realizado no seu ambiente natural, pois os fatos sociais têm que ser observados e analisados, inseridos no contexto aos quais pertencem, desempenhando o pesquisador um papel fundamental na observação, seleção, consolidação e análise dos dados gerados, como os diferentes tipos de dados são considerados importantes para a compreensão do fenômeno social em estudo.

\subsection{Procedimentos Para Coleta de Dados}

Foi feita uma pesquisa exploratória com o propósito de compreender melhor o problema de estudo e definir o objetivo da pesquisa. De acordo com Gil (2002), esse tipo de apuramento possibilita a análise das diversas posições acerca de um empecilho, além de serem desenvolvidas quase exclusivamente mediante fontes bibliográficas. Com isso, foi realizado levantamento de dados em literatura como artigos, livros, periódicos, dissertações, teses, artigos de sites de notícias, artigos em sites de prefeituras e similares.

\section{Resultados Obtidos}

Com isso, a pesquisa busca responder ao seguinte questionamento: "Como o PIX poderá ser uma alternativa de inovação na arrecadação do IPTU?”, a qual será discutida nos tópicos a seguir:

\subsection{Pagamento de impostos com o PIX}

O método de pagamento PIX é disponível para qualquer usuário de banco com acesso à internet. Seu desenvolvimento proporcionou melhoria na eficiência do setor público e promoveu viabilidades no dia a dia das pessoas. Por meio desse novo método de pagamento instantâneo, as entidades públicas podem coletar impostos com flexibilidade e pagar fornecedores, salários e benefícios. Tudo isso ocorrendo todos os dias, a qualquer hora ou momento do dia (BANCO CENTRAL DO BRASIL, 2021).

\subsection{O Processo De Arrecadação Do IPTU Atualmente}

Cada município regula o meio de pagamento através de leis orgânicas municipais. Logo, cada cidade tem os seus meios para pagamento. Com isso, serão apresentados como exemplo os meios de pagamento de quatro cidades: Cidade de Eusébio, localizada no Ceará; Jundiaí, localizada em São Paulo; Areal e Rio de Janeiro, localizadas no Rio de Janeiro. Levando em consideração que não se faz necessário apresentar todos os municípios do país pela extensa quantidade, abaixo segue os exemplos, como amostragem, das quatro cidades.

\subsubsection{Processo de Pagamento de IPTU na cidade de Eusébio - CE}

A Prefeitura de Eusébio é o primeiro município do Brasil a utilizar PIX para recebimento de tributos. Segundo o secretário de Finanças e Planejamento de Eusébio, Alexandre Cialdini, os boletos do IPTU, que podem ser impressos através do portal da Prefeitura, já trazem o $Q R$ Code que direciona para o pagamento com PIX. "Fizemos uma parceria com o Banco do Brasil. O Eusébio é a primeira cidade a utilizar esse sistema e a partir daqui o modelo será levado para outros municípios", destaca. (PREFEITURA DE 
EUSÉBIO, 2021)

Segundo o secretário, a orientação do prefeito Acilon foi que a Sefin encontrasse formas de facilitar a vida dos contribuintes. "Fomos orientados a buscar iniciativas tecnológicas que pudessem criar uma relação muito mais fácil com o contribuinte, para que pudessem pagar com facilidade seus tributos. Nessa linha, conseguimos fazer uma parceria com o Banco do Brasil e com uma empresa de tecnologia que está operando no município, para criar esse processo de pagamento através do PIX. Hoje, basta o contribuinte baixar o PIX pelo $Q R$ Code que consta no boleto através de seu celular, tablet ou computador e fazer o pagamento a qualquer hora do dia e qualquer dia da semana,” enfatiza. (PREFEITURA DE EUSÉBIO, 2021)

Cialdini assevera que a Sefin inicia essa campanha de pagamento do IPTU em dia para que o morador do EUSÉBIO abrace a cidade, pois, ao abraçar a cidade, estará abraçando também a responsabilidade que ele tem com o município. "O IPTU é a segunda principal fonte de receita do município e essa possibilidade de estar adimplente com o IPTU possibilita que o município possa manter sua ampla rede social em pleno funcionamento", argumentou. (PREFEITURA DE EUSÉBIO, 2021)

\subsubsection{Processo de Pagamento de IPTU na cidade de Jundiaí- SP}

A Prefeitura de Jundiaí passa a oferecer ao munícipe a opção de pagamento das parcelas do IPTU (Imposto Sobre a Propriedade Predial e Territorial Urbano) através do PIX, meio eletrônico e instantâneo de pagamentos e transferências bancárias. A novidade está disponível desde o início do mês e foi implantada a partir de um trabalho conjunto entre a Unidade de Gestão de Governo e Finanças e a Cijun (Companhia de Informática de Jundiaí). (PREFEITURA DE JUNDIAÍ,2021). Segundo José Antonio Parimoschi, gestor de Governo e Finança:

A implantação desse novo meio de pagamento vai ao encontro do que pregamos em Jundiaí: uma administração pública moderna e que agiliza a vida do munícipe no que diz respeito ao serviço público prestado [...] Estamos no caminho de tornar Jundiaí uma "Cidade Inteligente", na qual as inovações tecnológicas se integram cada vez mais ao nosso dia a dia (PREFEITURA DE JUNDIAÍ, 2021).

Entende-se por Cidade Inteligente o termo utilizado para designar o espaço urbano que é conduzido com fins de investimento em capital humano e social, para o desenvolvimento econômico e sustentável, à aplicação de tecnologias disponíveis para desenvolver e interconectar os serviços e a infraestrutura das cidades. Esses processos se constituem de forma inclusiva, transparente, inovadora e participativa, a fim de que ocorra a elevação do bem-estar dos cidadãos (CÂMARA DOS DEPUTADOS, 2021).

Segundo o coordenador da área de novos projetos da Cijun, Márcio Carpi, a aceitação foi positiva. "Desde a implantação, 1.171 pessoas pagaram parcelas com o PIX e mais de sete mil entraram no ambiente virtual para visualizar e conhecer essa nova opção." O coordenador diz que em breve outros tributos municipais também receberão a opção de pagamento por PIX. "É uma tecnologia emergente que veio para ficar", diz (PREFEITURA DE JUNDIAÍ, 2021).

\subsubsection{Processo de Pagamento de IPTU na cidade de Areal - RJ}


Foi regulamentado no dia 04/03/2021 pela prefeitura da cidade, em conjunto com o Banco do Brasil, a cidade de Areal como a primeira cidade do Estado do Rio de Janeiro e a segunda do país a receber o pagamento, além do carnê, via PIX (PREFEITURA DE AREAL,2021)

\subsubsection{Processo de Pagamento de IPTU na cidade do Rio de Janeiro - RJ}

Na cidade do Rio de Janeiro:

A partir de 2021, visando a redução dos gastos públicos, a Secretaria Municipal de Fazenda emitirá uma única guia com a Notificação de Lançamento do IPTU e/ou TCL, em substituição ao carnê. O contribuinte que optar pelo pagamento em cotas poderá pagar a primeira parcela com o código de barras disponível na guia de cobrança. As demais cotas deverão ser emitidas pela internet, no portal Carioca Digital (PREFEITURA DO RIO DE JANEIRO, 2021).

\section{Considerações Finais}

Conclui-se que a inovação no setor público apresenta-se essencial para que o setor em questão não somente acompanhe os avanços tecnológicos que surgem, mas, também, para que atualize seus procedimentos e serviços. Ademais, a inovação econômica no setor público acompanha os anseios da população em sistemas céleres, que tragam benefícios reais e duradouros, podendo até serem recursos para desburocratizar os atuais procedimentos.

Como afirma o Banco Central, o PIX é o meio de transferência mais utilizado no país, pois, além de ser de fácil acesso, ele oferece praticidade e agilidade. Dessa forma, é notório que o PIX poderá sim ser uma alternativa no processo de arrecadação do IPTU. Sendo um recurso que proporcionou avanços para alguns municípios, especialmente no que se refere à elevação da arrecadação. Ele é uma forma eficaz na qual o contribuinte consegue manter seus débitos em dia, pois ele é capaz de efetuar o pagamento do imposto em qualquer banco e em qualquer horário, sem a necessidade de pagar tarifas bancárias cobradas pelas instituições financeiras. O objetivo e maior ganho é oferecer aos contribuintes mais um canal de recolhimento de impostos.

O PIX, segundo o BACEN, é um sistema amplamente aceito pela população, com crescente adesão em termos de utilização e de valores transacionado, pois, além de ser prático, não tem as mesmas limitações que o DOC e o TED possuem, sejam de valor ou de prazo (com datas e dias úteis). Além disso, possui ainda o efeito secundário de proporcionar melhorias do atendimento ao cidadão em outros serviços, na medida em que torna o processo de arrecadação mais ágil, dispensando tempo da burocracia municipal para esses outros serviços. Sendo assim, o uso do PIX proporciona ao cidadão agilidade em seus pagamentos e conforto, uma vez que possibilita a contribuição de impostos em qualquer lugar. Contudo, o PIX não atende aos contribuintes que necessitam parcelar algum débito, isso ainda deve ser realizado por outros procedimentos e meios de pagamento.

A prefeitura de Eusébio relatou no seu site que, ao ser o primeiro município com a implantação do PIX, chegou mais próximo do munícipe e com isso facilitou a vida dos moradores. $\mathrm{O}$ modelo deu certo ao ponto de ser levado a outros municípios. Jundiaí, que 
está no momento de se tornar uma Cidade Inteligente, utilizou a oportunidade para seguir o modelo de Eusébio, que tem seu conceito de administração pública moderna e que agiliza a vida do munícipe. Ainda, a prefeitura de Areal é a primeira cidade no estado do Rio de Janeiro a implantar o sistema e utiliza do feito como slogan e busca uma administração moderna. Assim, como a Prefeitura de Jundiaí cita, o PIX abre uma porta de ser uma nova alternativa não só para recolhimento de tributos, mas também para quebra de etapa de serviços. Os boletos, como a cidade do Rio de Janeiro ainda utiliza, não possuem a mesma facilidade que o QR Code ou código que o PIX utiliza no quesito de leitura, pois precisam de maquinário. Cada código tem um custo, e, ainda que os bancos forneçam meios on-line, faz com que haja filas em bancos e lotéricas.

Sugerimos que pesquisas futuras possam explorar a investigação do presente trabalho, explorando conclusões baseadas em dados mais concretos, obtidos junto aos contribuintes, que visem captar a percepção desses sobre os benefícios obtidos no uso dessa ferramenta para pagamento de impostos e contribuições. O tema possibilita, ainda, o desenvolvimento de pesquisas práticas e normativas para melhoria nos processos de arrecadação pelo poder público. Em relação às pesquisas futuras, o trabalho elenca informações fundamentais no que concerne à forma inovadora de pagamento via PIX, podendo ser desencadeado para outros estudos, tais como: a adesão de novos entes, fim dos carnês impressos e redução de custos operacionais.

Além disso, tratando-se dos serviços da administração pública oferecidos à população, são permitidos alcance e agilidade, possibilitando melhoria no atendimento ao cidadão também em outros serviços, tais como a emissão ou reemissão de documentos como carteiras de identidade, habilitação, passaporte e outros que sejam recolhidos por guias. O uso do PIX proporciona ao cidadão agilidade em seus pagamentos e conforto, uma vez que possibilita o pagamento de impostos em qualquer lugar.

\section{Referências}

AREAL, P. Areal É A Cidade Pioneira Do Estado Do Rio A Receber Tributos Via PIX, 2021. Disponível em < https://areal.rj.gov.br/areal-e-a-cidade-pioneira-do-estado-dorio-a-receber-tributos-via-PIX/>. Acesso em 01 de setembro de 2021

BALEEIRO A; DERZI MAM. Direito tributário brasileiro. 11. ed. Rio de Janeiro: Forense; 2010. 1063 p.

BANCO CENTRAL DO BRASIL. O que é PIX? 2021. Disponível em: <https://www.bcb.gov.br/estabilidadefinanceira/PIX>. Acesso em: 11 de agosto de 2021.

BANCO CENTRAL DO BRASIL. PIX: há 1 ano facilitando pagamentos em todo o Brasil. 2021. Disponível em: < https://www.bcb.gov.br/detalhenoticia/590/noticia>. Acesso em: 20 de dezembro de 2021.

BANCO CENTRAL DO BRASIL. Relatório de Economia Bancária - PIX: o novo meio de pagamento brasileiro. 2020. Disponível em: <https://www.bcb.gov.br/content/publicacoes/Documents/reb/boxesreb2018/boxe_19_PIX.p df>. Acesso em 11 de agosto de 2021.

BANCO DO BRASIL. Estados e municípios recebem tributos via PIX por meio de 
\begin{tabular}{llllll}
\hline solução desenvolvida & pelo & BB. & 2021. & Disponível & em:
\end{tabular} $<$ https://www.bb.com.br/pbb/pagina-inicial/imprensa/n/63098/estados-e-municipiosrecebem-tributos-via-PIX-por-meio-de-solucao-desenvolvida-pelo-bb\#/>. Acesso em $11 \mathrm{de}$ agosto de 2021.

BRANDÃO, S.M.; BRUNO-FARIA, M.F. Inovação no setor público: análise da produção científica em periódicos nacionais e internacionais da área de administração. Revista de Administração Pública [online]. 2013, v. 47, n. 1, pp. 227-248.

BRASIL. Constituição Da República Federativa Do Brasil De 1988. Disponível em: <http://www.planalto.gov.br/ccivil_03/constituicao/constituicao.htm>. Acesso em: 11 de agosto de 2021.

BMG, B. O que é cartão de débito e como funciona. Disponível em < https://www.bancobmg.com.br/blog/conta-digital/o-que-e-cartao-de-debito-e-comofunciona/\#: :text=Para $\% 20 \mathrm{isso} \% 2 \mathrm{C} \% 20 \% \mathrm{C} 3 \% \mathrm{~A} 9 \% 20 \mathrm{importante} \% 20$ se,ou $\% 20$ pelo\%20apl icativo\%20do\%20meu_BMG./ >. Acesso em 18 de dezembro de 2021.

BUfFano, F. D. A., et al. Métodos De Pagamento Digital. Feira do Conhecimento. São Paulo, 2020

CAPUANO, E. A. Gestão por competências no setor público: experiências de países avançados e lições para o Brasil. Revista do Serviço Público, Brasília, v. 66, n. 3, p. 371394 , jul./set. 2015.

CAVALCANTE, P. et al. (Org.). Inovação no setor público: teoria, tendências e casos no Brasil. Brasília, DF: Ipea/Enap, 2017.

DOS DEPUTADOS, C. Cidades inteligentes [recurso eletrônico] : uma abordagem humana e sustentável / relatores Francisco Jr. (coordenador) ... [et al.] ; equipe técnica Leandro Alves Carneiro ... [et al.] (organizador). - 1. ed. - Brasília : Câmara dos Deputados, Edições Câmara, 2021. - (Série estudos estratégicos ; n. 12)

DUARTE, A. M.; CHAGAS, M. J. R. A Função Social Dos Impostos Municipais: Um Estudo Sobre A Arrecadação No Município De Iguatu-CE, Entre 2009 E 2014. Anais do Encontro Nacional de Ensino e Pesquisa do Campo de Públicas. v. 2, n. 2, 2017, pp. $2-18$.

EUSÉBIO, P. Eusébio é o primeiro município do Brasil a receber o IPTU pelo PIX. Disponível em: <http://eusebio.ce.gov.br/eusebio-e-o-primeiro-municipio-do-brasil-areceber-tributos-pelo-PIX/>. Acesso em 20 de dezembro de 2021

GIL, A. C. Como Elaborar Projetos de Pesquisa. 4. ed. São Paulo: Atlas, 2002

GODOY, A. S. Introdução à pesquisa qualitativa e suas possibilidades. São Paulo, $1995 . \quad$ Disponível em:< https:/www.scielo.br/j/rae/a/wf9cgwxvjplfvgpwnkcgnnc/?lang=pt\&format=pdf>

JUNDIAÍ, P. Prefeitura oferece opção de pagamento do IPTU via PIX. Disponível em: <https://jundiai.sp.gov.br/noticias/2021/07/14/prefeitura-oferece-opcao-de-pagamentodo-iptu-via-PIX/>. Acesso em 20 de dezembro de 2021 
LIMA, E.M.; REZENDE, A.J. Um estudo sobre a evolução da carga tributária no Brasil: uma análise a partir da Curva de Laffer. Interações (Campo Grande) [online]. 2019 , v. 20 , n. 1 , pp. $239-255$.

LIMA, H.; FRANCISCO, E.R. Revolução Nos Meios De Pagamento Digitais. GV Executivo, Rio De Janeiro. V.20. Jan/mar.2021. p. 22-25.2021.

MEDEIROS, M.; SOUZA, P. (2013), "Gasto público, tributos e desigualdade de renda no Brasil”. Texto para discussão n ${ }^{\circ} 1844$. Rio de Janeiro, Ipea.

NUBANK (2021), O que significa PIX? Disponível em < https://blog.nubank.com.br/oque-significa-PIX/>. Acesso em 02 de agosto de 2021.

NUBANK (2021). Qual é a diferença entre TED e DOC? Disponível em < https://blog.nubank.com.br/ted-e-doc-diferenca/ >. Acesso em 18 de dezembro de 2021.

NUBANK (2021). Qual a diferença entre o PIX e outros meios de pagamento? Disponível em <https://blog.nubank.com.br/PIX-diferenca-outros-meios-de-pagamento/>. Acesso em 18 de dezembro de 2021.

PLONSKI, G. A. Inovação em transformação. Estudos Avançados [online]. 2017, v. 31, n. 90 , pp. 7-21. Disponível em: <https://doi.org/10.1590/s0103-40142017.3190002>. ISSN 1806-9592. https://doi.org/10.1590/s0103-40142017.3190002. Acesso, 25 de Janeiro de 2022

QUEIROZ, R.G.M.; CKAGNAZAROFF, I.B. Inovação no setor público: uma análise do choque de gestão (2003-10) sob a ótica dos servidores e dos preceitos) teóricos relacionados a inovação no setor público. Revista de Administração Pública, v. 44, n. 3, p. 679-705, 2010.

RIO, P. IPTU, 2021. Disponível em < http://www.rio.rj.gov.br/web/smf/iptu1>. Acesso em 01 de setembro de 2021.

SANTOS, F.J.S.; SANO, H. Inovação no setor público: um olhar sobre os estudos brasileiros. Revista Interface, v.13, n.2, p.33-48, 2016.

SANTOS, R.R.; ROVER, S. Influência da governança pública na eficiência da alocação dos recursos públicos. Revista de Administração Pública [online]. 2019, v. 53, n. 4 pp. $732-752$.

SC, E. Banco Central revela que pagamentos digitais estão em ascensão no Brasil. Santa Catarina, 2020. Disponível em: < https://www.economiasc.com/2020/09/10/banco-central-revela-que-pagamentos-digitaisestao-em-ascensao-no-brasil/> Acesso em 19 de dezembro de 2021

SCHWELLA, E. Inovação no governo e no setor público: desafios e implicações para a liderança. Revista do Setor Público, v. 56, n. 3, p. 259-276, 2005.

SOARES, B. Professor da UERN orienta sobre o uso do PIX. 2020 Universidade do Estado do Rio Grande do Norte. Disponível em: <http://portal.uern.br/blog/professor-dauern-orienta-sobre-o-uso-do-PIX/>. Acesso em 11 de agosto de 2021. 
SOUZA, C. Políticas públicas: uma revisão da literatura. Sociologias, Porto Alegre, n. 16, p. 20-45, dez. 2006.

TORRES, K.R.B.O. et al. Evolução das políticas públicas para a saúde do idoso no contexto do Sistema Único de Saúde. Physis: Revista de Saúde Coletiva [online]. v. 30, n. 01, 2020, e300113.

WOLFFENBUTTEL, R. F. Inovação econômica: trajetórias e contribuições de uma agenda de pesquisa sociológica. Sociologias, Porto Alegre, ano 20, n. 48, maioago. 2018, p. 310-323 